\title{
TINJAUAN KUALITAS DAN DAMPAK EKONOMI KONSENTRASI TOTAL DISSOLVED SOLID (TDS) AIR DI AREA PERTAMBAKAN DESA BULUMANIS KIDUL
}

\author{
THE QUALITY AND ECONOMIC IMPACT REVIEW \\ OF TOTAL DISSOLVED SOLIDS CONCENTRATION \\ IN AQUACULTURE AREA BULUMANIS KIDUL VILLAGE
}

\author{
Herna Octivia Damayanti \\ Kantor Penelitian dan Pengembangan Kabupaten Pati \\ Email : octivia_oc@yahoo.co.id
}

Naskah Masuk: 15 September 2014 Naskah Revisi: 29 September 2014 Naskah Diterima: 13 Oktober 2014

\begin{abstract}
High Total Dissolved Solid (TDS) concentration can increase salinity ultimately reduce the availability of dissolved oxygen (DO). Objectives of the research are to Bulumanis Kidul village aquaculture area : (1) determine the irrigation channels TDS concentration, (2) determine the fishpond pools TDS concentration, (3) conduct the aquaculture economic review to fishpond pools water exchange. This research used descriptive method. Primary data is TDS data of water samples taken on July 7, 2013 and secondary data from the relevant documents. Sampling of water in Bugag and Daleman irrigation canal, Block Kali Bugag 6 samples and Block Kali Daleman 3 samples. Analysis data by descriptive analysis. TDS concentration data of water sample compared with Class III water quality criteria in the Goverment Regulation Number 82 of 2001. While results of literature and documents study are presented in narrative form. The results are : (1) TDS concentration in Bugag and Daleman irrigation canal not fulfill the Class III water quality criteria, (2) TDS concentration in and Block Kali Bugag and Block Kali Daleman fishpond pool not fulfill Class III water quality criteria, (3) the water exchange or mixing in a short time due to the unfavorable water source conditioncan reduce the business profit.
\end{abstract}

Keywords: bulumanis kidul, TDS, economic review

\section{ABSTRAK}

Konsentrasi Total Dissolved Solids (TDS) tinggi dapat meningkatkan salinitas yang akhirnya mengurangi ketersediaan oksigen terlarut (DO). Tujuan penelitian adalah untuk area pertambakan Desa Bulumanis kidul : (1) mengetahui konsentrasi TDS saluran irigasi, (2) mengetahui konsentrasi TDS kolam tambak, (3) melakukan tinjauan ekonomi terhadap penggantian air kolam tambak. Penelitian ini menggunakan metode deskriptif. Data primer yaitu data TDS sampel air yang diambil pada 7 Juli 2013 dan data sekunder dari dokumen yang relevan. Pengambilan sampel air di saluran irigasi Bugag dan Daleman, Blok Kali Bugag sebanyak 6 sampel dan Blok Kali Daleman sebanyak 3 sampel. Analisis data secara deskriptif. Data konsentrasi TDS sampel air dibandingkan dengan kriteria mutu air kelas III dalam PP No. 82 Tahun 2001. Sedangkan hasil studi literatur dan dokumen disajikan dalam bentuk narasi. Hasil penelitian adalah (1) konsentrasi TDS di saluran irigasi Bugag dan Daleman tidak memenuhi kriteria mutu air kelas III; (2) konsentrasi TDS di kolam tambak Blok Kali Bugag dan Blok Kali Daleman tidak memenuhi kriteria mutu air kelas III; (3) penggantian atau pencampuran air dalam waktu yang singkat karena kondisi sumber air yang kurang baik dapat mengurangi keuntungan usaha.

Kata kunci: bulumanis kidul, TDS, tinjauan ekonomi 


\section{PENDAHULUAN}

Desa Bulumanis Kidul merupakan salah satu Desa di Kecamatan Margoyoso Kabupaten Pati yang di sebelah utara berbatasan dengan Laut Jawa, sebelah timur berbatasan dengan Desa Pangkalan, sebelah selatan berbatasan dengan Desa Pohijo dan Sekarjalak, sebelah barat berbatasan dengan Desa Bulumanis Lor (Bappeda dan IPB, 2001). Desa Bulumanis Kidul yang berbatasan dengan laut mempunyai wilayah pesisir. Aktifitas masyarakat yang memanfaatkan wilayah pesisir adalah pertambakan. Luas tambak Desa Bulumanis Kidul adalah 217, 7359 Ha (Bulumanis Kidul, 2013). Area pertambakan di Desa Bulumanis Kidul mendapat pasokan air melalui saluran irigasi yang berasal dari laut. Saluran irigasinya adalah Saluran Bugag, Saluran Daleman dan Saluran Gumuk. Saluran Bugag berada berdekatan dengan muara Sungai Suwatu, Saluran Daleman berada di tengah area pertambakan dan Saluran Gumuk berada berdekatan dengan muara Sungai Pangkalan. Area pertambakan Desa Bulumanis Kidul dibagi menjadi 9 blok yaitu blok kali Suwatu sebanyak 16 petak tambak, blok kali Bugag sebanyak 41 petak tambak, blok kali Daleman sebanyak 53 petak tambak, blok kali Gumuk sebanyak 26 petak tambak, blok Turi sebanyak 24 petak tambak, blok kali Basir sebanyak 45 petak tambak, blok Perangkat Lor sebanyak 13 petak tambak, blok Perangkat sebanyak 12 petak tambak dan blok Songko sebanyak 18 petak tambak (Damayanti, 2013).

Desa Bulumanis Kidul dilalui oleh Sungai Suwatu yang bermuara di sekitar area pertambakan. Damayanti (2013) menyatakan bahwa jika membicarakan tentang Desa Bulumanis Kidul, maka tidak akan terlepas dari Sungai Suwatu. Hal ini dikarenakan Sungai Suwatu merupakan sungai yang mengalir di Desa Bulumanis Kidul dan melalui area pertambakan. Berdasarkan penelitian Astuti (2012), kondisi status mutu air Sungai Suwatu dalam kategori tercemar berat karena Sungai Suwatu digunakan sebagai tempat pembuangan baik limbah tapioka, limbah peternakan maupun limbah rumah tangga.

Aliran Sungai Suwatu sendiri pada akhirnya akan bertemu dengan laut di muara. Damayanti (2012) juga menyatakan bahwa di muara akan terakumulasi semua bahan buangan yang berasal dari sepanjang aliran Sungai Suwatu dan dari laut yang terbawa oleh pergerakan arus, sehingga berbagai macam bahan buangan yang terakumulasi di muara Sungai Suwatu akan menyebar ke laut.

Penelitian Damayanti menemukan fakta bahwa status mutu air laut pantai Bulumanis Kidul dengan menggunakan perhitungan indeks pencemaran (IP) dalam kondisi tercemar sedang. Pasokan air area pertambakan di Desa Bulumanis Kidul diperoleh dari air laut. Saluran irigasi melalui Saluran irigasi Bugag dan Daleman sebagai pemasok air untuk kolam tambak, maka kualitas air saluran irigasi Bugag dan Daleman perlu mendapat perhatian.

Menurut Kordi dan Tancung (2007), salah satu faktor penentu keberhasilan budi daya tambak adalah kondisi kualitas air tambak. Jika kualitas air tambak tidak baik maka dapat berakibat pada kematian ikan yang dibudi dayakan. Salah satu parameter penopang kehidupan ikan budi daya yaitu Total Dissolved Solid (TDS), karena TDS disebabkan oleh bahan anorganik berupa ion-ion yang biasa ditemukan di perairan. Effendi (2003) menyatakan bahwa air laut yang memiliki nilai TDS yang tinggi akan mengakibatkan salinitas dan daya hantar listrik yang tinggi. Oktaviana (2008) 
menyatakan jika salinitas tinggi maka konsentrasi DO menjadi rendah, atau sebaliknya jika salinitas rendah DO menjadi tinggi. Dengan demikian, jika konsentrasi TDS tidak dijaga maka dapat menimbulkan efek beruntun yang pada akhirnya mengurangi ketersediaan oksigen terlarut (DO) untuk ikan budi daya.

Berdasarkan latar belakang tersebut, maka tujuan penelitian ini adalah: (1) mengetahui konsentrasi TDS saluran irigasi, (2) mengetahui konsentrasi TDS kolam tambak, (3) melakukan tinjauan ekonomi terhadap penggantian air kolam tambak.

\section{TINJAUAN PUSTAKA}

\section{Tambak}

Pengertian tambak sendiri adalah kolam buatan, biasanya di daerah pantai yang diisi air dan dimanfaatkan sebagai sarana budi daya perairan (akuakultur). Penyebutan "tambak" ini biasanya dihubungkan dengan air payau atau air laut (Minawati, 2013). BPS dalam Widowati (2004) mengartikan tambak sebagai lahan yang digunakan untuk melakukan pemeliharaan ikan, udang, fauna atau biota lainnya. Terletak tidak jauh dari laut dan air asin atau payau, merupakan campuran antara air laut dan air tawar.

\section{Penurunan Kualitas Air Tambak}

Pencemaran terhadap air tambak yang mempengaruhi kualitas air yang digunakan untuk budi daya perikanan disebabkan oleh beberapa aktivitas utama antara lain (1) kegiatan domestik, (2) kegiatan industri dan (3) kegiatan pertanian dan perkebunan (Syofyan dkk, 2011). Menurut Kordi dan Tancung (2007), penyebab menurunnya kualitas air tambak adalah :
1). Padat penebaran

Padat penebaran berpengaruh nyata dengan penurunan kualitas air. Semakin tinggi padat penebaran semakin mempercepat penurunan kualitas air, sehingga pada tambak yang menerapkan padat penebaran tinggi membutuhkan pengelolaan kualitas air yang lebih ekstra. Karena selain banyaknya sisa metabolisme biota, juga tertimbunnya sisa pakan di dasar tambak dan jumlah oksigen semakin menurun sejalan dengan kebutuhan konsumsi oksigen.

2). Pakan yang berlebihan dan akumulasi bahan organik

Kualitas air cepat mengalami penurunan bila sisa pakan yang tertimbun sangat besar. Bila penimbunan pakan di dasar tambak tidak segera diantisipasi, maka sebagai bahan organik akan terjadi proses dekomposisi. Dalam proses dekomposisi akan membutuhkan sejumlah besar oksigen. kebutuhan oksigen ini semakin besar dengan makin meningkatnya kandungan limbah dari bahan organik (didalamnya termasuk sisa pakan). Bila suplai oksigen tidak cukup, kondisi anaerobik pada dasar tambak tidak dapat dihindarkan. Tentu ini sangat membahayakan biota budi daya.

3). Pengelolaan sebelum penebaran

Sebelum penebaran benih, tambak harus dipersiapkan dengan baik. Baik tambak baru maupun tambak lama, bila pengelolaan sebelum penebaran tidak memadai, maka kualitas air cepat mengalami penurunan.

4). Pengelolaan air

Pengelolaan air meliputi air sebelum dimasukkan ke dalam tambak maupun setelah berada di dalam tambak. 
Bila pengelolaan air di dua tempat ini tidak memenuhi syarat kualitas air, maka cepat sekali mengalami penurunan mutu.

5). Kondisi air sumber

Kualitas air di dalam tambak juga sangat tergantung pada kualitas air sumber, berupa sungai, danau, waduk, kawasan pesisir dan sebagainya. Bila tambak memperoleh air sumber yang bermutu rendah, maka semakin cepat mengalami penurunan, kecuali air tersebut di-treatment lebih dahulu sebelum dialirkan ke tambak.

6). Perubahan cuaca

Pergantian musim harus diperhatikan dan diwaspadai. Hal ini disebabkan kuantitas dan kualitas air pada musim kemarau dan penghujan yang sering tidak sama. Belum lagi proses kimia dan fisika yang terjadi di perairan tambak dari kedua musim tersebut, sehingga perubahan musim berakibat kualitas air sangat fluktuatif.

\section{Total Dissolved Solids (TDS)}

Total Dissolved Solids (TDS) adalah bahan-bahan terlarut (diameter < $10^{-6} \mathrm{~mm}$ ) dan koloid (diameter $10^{-6} \mathrm{~mm}$ $10^{-3} \mathrm{~mm}$ ) yang berupa senyawa-senyawa kimia dan bahan-bahan lain, yang tidak tersaring pada kertas saring berdiameter 0,45 $\mu \mathrm{m}$ (Roa dalam Effendi, 2003). TDS biasanya disebabkan oleh bahan anorganik yang berupa ion-ion yang biasa ditemukan di perairan. Nilai TDS perairan sangat dipengaruhi oleh pelapukan batuan, limpasan dari tanah dan pengaruh antropogenik (berupa limbah domestik dan industri).
Baku mutu TDS yang digunakan berdasarkan kriteria mutu air kelas III sebesar $1.000 \mathrm{mg} / \mathrm{l}$. Konsentrasi TDS terlalu tinggi atau terlalu rendah, dapat menghambat pertumbuhan kehidupan dalam air dan dapat menyebabkan kematian. TDS konsentrasi tinggi juga dapat mengurangi kejernihan air atau dengan kata lain meningkatkan kekeruhan air yang selanjutnya akan menghambat penetrasi cahaya mahahari ke kolom air dan akhirnya berpengaruh terhadap proses fotosintesis di perairan. Selain itu, gabungan TDS dengan senyawa beracun dan logam berat menyebabkan peningkatan suhu air (Effendi, 2003).

\section{METODE PENELITIAN}

Penelitian ini menggunakan metode deskriptif. Sumber data yang digunakan berupa data primer dan data sekunder. Data primer yaitu data TDS dari sampel air yang diambil pada 7 Juli 2013. Sedangkan data sekunder diperoleh dari studi literatur terhadap dokumen yang relevan.

Pengambilan sampel air ditentukan dengan metode selektif sampel yang memenuhi kriteria, yaitu tambak masih digunakan budi daya ikan (Paramitha dan Sudarmaji, 2007). Sampel air diambil di saluran irigasi dan kolam-kolam tambak. Untuk saluran irigasi yaitu Saluran irigasi Bugag dan Daleman. Sedangkan sampel air di kolam tambak diambil di Blok Kali Bugag sebanyak 6 sampel (B1, B2, B3, B4, B5, B6) dan Blok Kali Daleman sebanyak 3 sampel (D1, D2, D3). Koordinat lokasi dan peta lokasi pengambilan sampel air disajikan pada Tabel 1 dan Gambar 1. 
Tabel 1.

LokasiPengambilanSampel Air

\begin{tabular}{|c|c|c|c|}
\hline No & Stasiun & Lintang (LS) & Bujur (BT) \\
\hline 1 & Bugag & $6^{0} 36^{\prime} 18.50^{\prime \prime}$ & $111^{0} 05^{\prime} 10.89^{\prime \prime}$ \\
\hline 2 & B1 & $6^{0} 36^{\prime} 13.10^{\prime \prime}$ & $111^{0} 05^{\prime} 11.05^{\prime \prime}$ \\
\hline 3 & B2 & $6^{0} 36^{\prime} 10.52^{\prime \prime}$ & $111^{0} 05^{\prime} 09.53^{\prime \prime}$ \\
\hline 4 & B3 & $6^{0} 36^{\prime} 09.41^{\prime \prime}$ & $111^{0} 05^{\prime} 09.11^{\prime \prime}$ \\
\hline 5 & B4 & $6^{0} 36^{\prime} 20.38^{\prime \prime}$ & $111^{0} 05^{\prime} 12.65^{\prime \prime}$ \\
\hline 6 & B5 & $6^{0} 36^{\prime} 23.35^{\prime \prime}$ & $111^{0} 05^{\prime} 13.13^{\prime \prime}$ \\
\hline 7 & B6 & $6^{0} 36 ’ 20.82 ”$ & $111^{0} 05^{\prime} 19.03$ " \\
\hline 8 & Daleman & $6^{0} 36^{\prime} 23.41^{\prime \prime}$ & $111^{0} 05^{\prime} 11.94 "$ \\
\hline 9 & D1 & $6^{0} 36$ '27.11" & $111^{0} 05^{\prime} 12.27^{\prime \prime}$ \\
\hline 10 & D2 & $6^{0} 36^{\prime} 30.88^{\prime \prime}$ & $111^{0} 05^{\prime} 13.17^{\prime \prime}$ \\
\hline 11 & D3 & $6^{0} 36^{\prime} 33.96 "$ & $111^{0} 05^{\prime} 13.08^{\prime \prime}$ \\
\hline
\end{tabular}

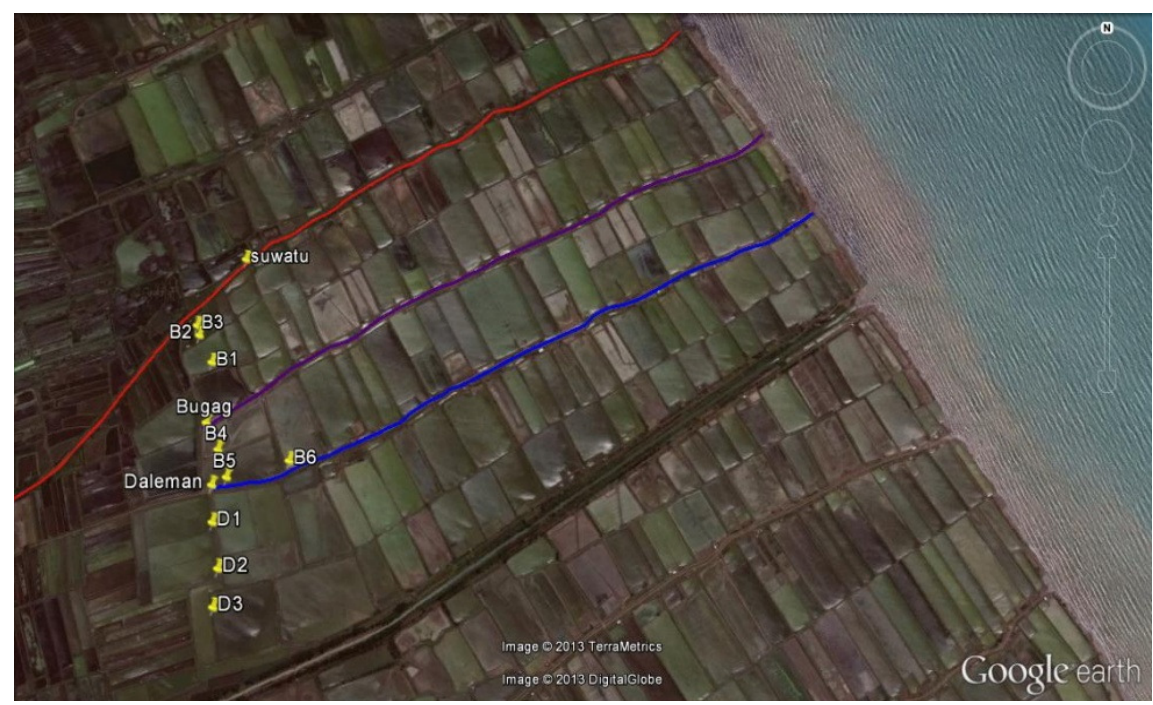

Gambar 1.

Peta Lokasi Penelitian

Sumber: Pengolahan Data (2013).

Untuk mendapatkan konsentrasi TDS, sampel air diuji laboratorium di Wahana Laboratorium Semarang. Analisis data dilakukan secara deskriptif. Untuk data konsentrasi TDS sampel air dibandingkan dengan kriteria mutu air kelas III dalam PP No. 82 Tahun 2001, sedangkan untuk hasil studi literatur dan dokumen disajikan dalam bentuk narasi.

\section{HASIL DAN PEMBAHASAN}

\section{TDS Saluran Bugag dan Saluran Daleman}

Sebagai sumber pasokan air untuk kolam tambak di Desa Bulumanis Kidul, konsentrasi TDS saluran irigasi perlu mendapat perhatian. Konsentrasi TDS Saluran irigasi Bugag dan Daleman disajikan pada Tabel 2 . 
Tabel 2.

Konsentrasi TDS Saluran Irigasi Bugag dan Daleman

\begin{tabular}{|c|c|c|c|c|}
\hline \multirow[b]{2}{*}{ No } & \multirow{2}{*}{$\begin{array}{c}\text { Saluran } \\
\text { Irigasi }\end{array}$} & \multicolumn{2}{|c|}{ Konsentrasi TDS (mg/l) } & \multirow[b]{2}{*}{ Keterangan } \\
\hline & & Sampling & $\begin{array}{c}\text { Kriteria Mutu } \\
\text { Air Kelas III }\end{array}$ & \\
\hline 1 & Bugag & 5.330 & \multirow{2}{*}{1.000} & Tidak Memenuhi \\
\hline 2 & Daleman & 4.840 & & Tidak Memenuhi \\
\hline
\end{tabular}

Konsentrasi TDS saluran irigasi Bugag $5.330 \mathrm{mg} / \mathrm{l}$, jika dibandingkan dengan kriteria mutu air kelas III untuk perikanan maka konsentrasi TDS ini tidak memenuhi kriteria tersebut. Konsentrasi TDS yang terdapat pada kriteria mutu air kelas III adalah $1.000 \mathrm{mg} / \mathrm{l}$ sehingga konsentrasi TDS saluran Bugag ini bernilai 5 kali lipat dari ketentuan. Sedangkan untuk konsentrasi TDS saluran irigasi Daleman sebesar 4.840 $\mathrm{mg} / \mathrm{l}$ dan bernilai 4 kali lipat bahkan hampir 5 kali lipat dari kriteria mutu air kelas III.

Effendi (2003) menyatakan bahwa nilai TDS perairan sangat dipengaruhi oleh pelapukan batuan, limpasan dari tanah, dan pengaruh antropogenik (berupa limbah domestik dan industri). Air yang mengalir di saluran irigasi berasal dari laut, dan jarak pengambilan sampel dari laut $\pm 3 \mathrm{~km}$ sehingga sangat memungkinkan sepanjang aliran air terjadi gerusan tanah bibir saluran yang menyebabkan konsentrasi TDS meningkat. Selain itu, konsentrasi TDS ini juga dipengaruhi oleh keberadaan ion- ion yang berada di perairan (Effendi, 2003). Keberadaan ion-ion ini berasal dari limbah domestik maupun industri. Contoh ion yang terkandung dalam air saluran irigasi adalah sulfat dan nitrat. Ion sulfat dan nitrat ini mengandung unsur sulfur dan nitrogen yang terkandung dalam air saluran irigasi di Desa Bulumanis Kidul.

Damayanti (2013) menemukan bahwa unsur sulfur dan nitrogen terdapat di air saluran irigasi dalam bentuk asam sulfida dan nitrit, sehingga tidak menutup kemungkinan kedua unsur ini akan terdegradasi atau terikat dengan unsur lain membentuk ion sulfat dan nitrat yang menyebabkan terjadinya peningkatan konsentrasi TDS di air saluran irigasi Desa Bulumanis Kidul.

\section{TDS Blok Kali Bugag}

Pengambilan sampel air pada kolam tambak Blok Kali Bugag berjumlah 6 sampel.

Konsentrasi TDS di kolam tambak Blok Kali Bugag disajikan pada Tabel 3. 
Tabel 3.

Konsentrasi TDS Kolam Tambak Blok Kali Bugag

\begin{tabular}{ccccc}
\hline & Saluran & \multicolumn{2}{c}{ Konsentrasi TDS (mg/l) } & Keterangan \\
\cline { 3 - 4 } No & $\begin{array}{c}\text { Irigasi } \\
n n n n n\end{array}$ & Sampling & $\begin{array}{c}\text { Kriteria Mutu } \\
\text { Air Kelas III }\end{array}$ & \\
\hline 1 & B1 & 5.050 & & Tidak Memenuhi \\
2 & B2 & 5.680 & & Tidak Memenuhi \\
3 & B3 & 3.670 & $\mathbf{1 . 0 0 0}$ & Tidak Memenuhi \\
4 & B4 & 5.100 & & Tidak Memenuhi \\
5 & B5 & 5.680 & & Tidak Memenuhi \\
6 & B6 & 4.500 & & Tidak Memenuhi \\
\hline
\end{tabular}

Sumber: Pengolahan Data (2013).

Konsentrasi TDS stasiun B1 5.050 mg/l, jika dibandingkan dengan kriteria mutu air kelas III untuk perikanan 1.000 mg/l maka konsentrasi TDS stasiun B1 tidak memenuhi kriteria dan bernilai 5 kali lipat dari ketentuan. Konsentrasi TDS stasiun B2 $5.680 \mathrm{mg} / \mathrm{l}$, konsentrasi ini tidak memenuhi kriteria dan bernilai 5 kali lipat. Untuk stasiun B3 konsentrasi TDS $3.670 \mathrm{mg} / \mathrm{l}$ dan tidak memenuhi kriteria, selain itu konsentrasi ini bernilai 3 kali lipat dari ketentuan. Stasiun B4 konsentrasi TDS $5.100 \mathrm{mg} / \mathrm{l}$, tidak memenuhi kriteria dan bernilai 5 kali lipat dari ketentuan. Stasiun B5 konsentrasi TDS $5.680 \mathrm{mg} / \mathrm{l}$, tidak memenuhi kriteria dan bernilai 5 kali lipat dari ketentuan. Stasiun B6 konsentrasi TDS 4.500 mg/l, tidak memenuhi kriteria dan bernilai 4 kali lipat dari ketentuan.
Konsentrasi TDS dalam air kolam tambak berasal dari sumber air yang telah mengandung TDS tinggi. Selain itu, berasal dari sisa pakan dan kotoran yang membusuk dan menghasilkan unsur nitrogen dan sulfur yang dapat terikat dengan oksigen menjadi sulfat dan nitrat, sehingga meningkatkan konsentrasi TDS dalam air kolam tambak. Sebaliknya jika konsentrasi TDS dalam air kolam tambak menurun disebabkan terjadinya pengendapan di dasar kolam sehingga di permukaan air kolam kandungan ionionnya sedikit dan konsentrasi TDS menjadi turun.

\section{TDS Blok Kali Daleman}

Pengambilan sampel air di kolam tambak Blok Kali Daleman berjumlah 3 sampel. Konsentrasi TDS dikolam tambak Blok Kali Daleman disajikan pada Tabel 4. 
Tabel 4.

Konsentrasi TDS Kolam Tambak Blok Kali Daleman

\begin{tabular}{ccccc}
\hline & Saluran & \multicolumn{2}{c}{ Konsentrasi TDS (mg/l) } & \\
\cline { 3 - 4 } No & $\begin{array}{c}\text { Irigasi } \\
n n n n n\end{array}$ & Sampling & $\begin{array}{c}\text { Kriteria Mutu } \\
\text { Air Kelas III }\end{array}$ & Keterangan \\
\hline 1 & D1 & 5.000 & & Tidak Memenuhi \\
2 & D2 & 4.660 & $\mathbf{1 . 0 0 0}$ & Tidak Memenuhi \\
3 & D3 & 3.840 & & Tidak Memenuhi \\
\hline
\end{tabular}

Sumber: Pengolahan Data (2013).

Konsentrasi TDS stasiun D1 5.000 $\mathrm{mg} / \mathrm{l}$, jika dibandingkan dengan kriteria mutu air kelas III untuk perikanan 1.000 $\mathrm{mg} / \mathrm{l}$ maka konsentrasi TDS stasiun D1 tidak memenuhi kriteria dan bernilai 5 kali lipat dari ketentuan. Stasiun D2 konsentrasi TDS $4.660 \mathrm{mg} / \mathrm{l}$, tidak memenuhi kriteria dan bernilai 4 kali lipat. Untuk stasiun D3 konsentrasi TDS $3.840 \mathrm{mg} / \mathrm{l}$, tidak memenuhi kriteria dan bernilai 3 kali lipat bahkan hampir 4 kali lipat dari ketentuan.

Sama halnya dengan kondisi pada Blok Kali Bugag, konsentrasi TDS dalam air kolam tambak di Blok Kali Daleman juga berasal dari sumber air yaitu saluran irigasi Daleman yang mengandung TDS tinggi dan dari sisa pakan dan kotoran yang membusuk dan menghasilkan unsur nitrogen dan sulfur. Penurunan konsentrasi TDS dalam air kolam tambak disebabkan terjadinya pengendapan di dasar kolam. Untuk stasiun D3 konsentrasi TDS lebih rendah dari saluran irigasi juga disebabkan karena dilakukan penggantian dan pencampuran air sehingga sisa pakan dan kotoran dalam air menjadi berkurang.

\section{Tinjauan Ekonomi Penggantian Air Kolam Tambak}

Dalam penelitian ini, parameter kualitas air yang diamati adalah TDS, dan berdasarkan hasil pengamatan seperti diketahui bahwa konsentrasi TDS sampel yang diambil di area pertambakan Desa
Bulumanis Kidul baik di saluran irigasi maupun kolam tambak ternyata tidak memenuhi kriteria mutu air kelas III untuk budi daya perikanan. Konsentrasi TDS semua sampel air telah melampaui kriteria (berada diatas kriteria) yang ditetapkan, dengan kata lain kolam tambak kondisinya keruh. Kordi dan Tancung (2007) menyatakan bahwa air merupakan faktor penentu daya dukung kolam dan tambak. Jika mutu air baik, daya dukung kolam dan tambak akan semakin tinggi pula, sebaliknya jika mutu air rendah maka daya dukungnya pun rendah. Untuk menjaga mutu air, terutama di tambak, maka salah satu caranya adalah penggantian air tambak.

Damayanti (2013) melakukan

perhitungan ekonomi terhadap penggantian air tambak yang dilakukan di area pertambakan Desa Bulumanis Kidul. Hasil perhitungannya adalah jika ditinjau dari besar biaya operasional yang harus dikeluarkan untuk melakukan penggantian air, maka terkait dengan biaya untuk sewa pompa dan penggunaan bahan bakar. Biaya sewa pompa per unit adalah Rp200.000,00 dengan estimasi penggunaan bahan bakar 10-12 liter solar atau Rp55.000,00 sampai dengan Rp66.000,00 (harga solar Rp5.500,00). Dengan demikian biaya yang dibutuhkan untuk sewa pompa dan bahan bakar untuk sekali pakai adalah sebesar Rp255.000,00 
sampai dengan Rp266.000,00 atau sekitar. Jika kualitas air kurang baik maka akan lebih sering dilakukan penggantian air. Menurut penuturan petambak, rata-rata penggantian air dalam 1 siklus tanam yaitu 3 kali atau jika dinominalkan sebesar Rp765.000,00 sampai dengan Rp798.000,00 (3,1\%-3,3\% dari jumlah seluruh biaya yang dikeluarkan), sedangkan jika kualitas air kurang baik maka penggantian air dapat dilakukan hingga 5-6 kali dalam 1 siklus tanam atau jika dinominalkan sebesar Rp1.530.000,00 sampai dengan Rp1.596.000,00 (6,2\%-6,5\% dari jumlah seluruh biaya yang dikeluarkan). Semakin sering dilakukan penggantian air tidak akan bagus bagi perkembangan ikan budi daya karena ikan dapat menjadi stres dan membutuhkan energi untuk dapat menyesuaikan diri dengan kondisi air yang baru sehingga mengurangi kecepatan pertumbuhan dan akibatnya ikan tidak akan mencapai ukuran optimal yang diharapkan petambak saat panen. Selain itu, jika penggantian air sering dilakukan akan menyebabkan bertambahnya biaya yang dikeluarkan petambak dan akan berakibat pada jumlah pendapatan yang diperoleh. Dengan demikian, kualitas air menjadi komponen penting dalam kegiatan usaha budi daya perikanan tambak karena dapat mempengaruhi keuntungan yang diperoleh.

\section{KESIMPULAN DAN SARAN}

\section{Kesimpulan}

1. Konsentrasi TDS di saluran irigasi, baik saluran irigasi Bugag maupun
Daleman tidak memenuhi kriteria mutu air kelas III.

2. Konsentrasi TDS di kolam tambak, baik Blok Kali Bugag dan Blok Kali Daleman tidak memenuhi kriteria mutu air kelas III.

3. Penggantian atau pencampuran air dalam waktu yang singkat karena kondisi kualitas sumber air yang kurang baik dapat mengurangi keuntungan usaha yang dijalankan petambak. Dari segi perhitungan usaha, kualitas air menjadi komponen penting dalam kegiatan usaha budi daya perikanan tambak karena dapat mempengaruhi keuntungan yang diperoleh.

\section{Saran}

1. Bagi Petambak di Desa Bulumanis Kidul : tidak berlebihan dalam memberikan pakan, tetapi disesuaikan dengan perkembangan dan pertumbuhan ikan yang dibudi dayakan.

2. Bagi Dislautkan, DPU dan Pemerintah desa Bulumanis Kidul : perlu dirancang sebuah cara untuk mengatur pola penggantian dan pembuangan air tambak, agar air yang telah dibuang dari suatu tambak tidak diambil kembali oleh tambak lain pada waktu yang berdekatan. Cara pengaturan dapat dengan cara pemberian tanda (berupa bendera) jika melakukan penggantian air sehingga petambak lain tidak melakukan pengambilan air dari saluran irigasi.

3. Bagi pemerintah Desa : dibuat sebuah peraturan tertulis tentang larangan dan sanksi tegas terhadap pembuangan limbah peternakan maupun limbah rumah tangga ke sungai. 


\section{DAFTAR PUSTAKA}

Astuti, A. D. 2012. Status Mutu Air Sungai Suwatu di Kecamatan Margoyoso Kabupaten Pati. Jurnal Litbang, 8(2) : 110-116.

Bappeda Kabupaten Pati dan Institut Pertanian Bandung. 2001. Album Peta Pemetaan Potensi

Sumberdaya Pesisir Dan Laut Wilayah Kabupaten Pati. Pati.

Bulumanis Kidul. 2013. Rekapitulasi

Data Tambak Bulumanis Kidul.

Pati.

Damayanti, H. O. 2013. Inventarisasi Area Pertambakan Desa Bulumanis Kidul Kecamatan Margoyoso. Kantor Penelitian dan Pengembangan Kabupaten Pati. Pati.

2013. Kualitas Air

Tambak, Kasus Kematian Ikan dan Tinjauan Ekonomi Budi daya Tambak di Desa Bulumanis Kidul Kecamtan Margoyoso. Seri Bunga Rampai, Pembangunan Daerah Berkelanjutan di Kabupaten Pati : 1-24.

2012. Kualitas Muara Sungai Suwatu Ditinjau Dari Parameter Kimia-Fisika. Jurnal Litbang, 8(3): 225-233.

2013. Pengaruh Jarak dari Saluran Irigasi Bugag Terhadap Kualitas Air Tambak Desa Bulumanis Kidul Kecamatan Margoyoso. Jurnal Litbang, IX(3) : 216-225.
2013. Status Mutu Air Laut di Pantai Bulumanis Kidul Kabupaten Pati. Jurnal Manusia dan Lingkungan, 20(3): 359-367.

Effendi, H. 2003. Telaah Kualitas Air Bagi Pengelolaan Sumber Daya dan Lingkungan Perairan. Yogyakarta: Kanisius.

Kordi, M. G. H dan A. B. Tancung. 2007. Pengelolaan Kualitas Air Dalam Budi Daya Perairan. Jakarta: Rineka Cipta.

Minawati, L. F. 2013. Budi daya Ikan Air Tawar Di Desa Selajambe Cisaat Kabupaten Sukabumi. Skripsi. Universitas Pendidikan Indonesia. Bandung : Universitas Pendidikan Indonesia.

Oktaviana, H. 2008. Pengaruh Kontraksi Penampang Saluran Terhadap Kualitas Fisik Air Sungai Studi Kasus: Sungai Sugutamu. Skripsi. Departemen Teknik Sipil. Depok : Universitas Indonesia.

Paramitha, I. dan Sudarmaji. 2007. Hubungan Jarak Terhadap Kualitas Kimia Air Tambak Dan Keluhan Kesehatan Masyarakat Konsumen Ikan Hasil Tambak Di Sekitar Tempat Pembuangan Akhir Sampah Benowo. Jurnal Kesehatan Lingkungan, 4(2): 39-48.

Syofyan, I, Usman dan Polaris Nasution. 2011. Studi Kualitas Air Untuk Kesehatan ikan Dalam Budi daya Perikanan Pada Aliran Sungai Kampar Kiri. Jurnal Perikanan dan Kelautan, Vol 16 (1) : 64-70. 
Widowati, L. L. 2004. Analisis Kesesuaian Perairan Tambak Di Kabupaten Demak Ditinjau Dari Aspek Produktivitas Primer Menggunakan Penginderaan Jauh. Tesis. Program Studi Magister Manajemen Sumberdaya Pantai. Semarang : Universitas Diponegoro.

\section{BIODATA PENULIS}

Herna Octivia Damayanti, lahir 6 Oktober 1985 di kota Kudus Jawa Tengah. Pendidikan S1 Program Studi Oseanografi Jurusan Ilmu Kelautan Fakultas Perikanan dan Ilmu Kelautan Universitas Diponegoro tahun 2009. Saat ini bekerja sebagai Peneliti di Kantor Penelitian dan Pengembangan Kabupaten Pati. 